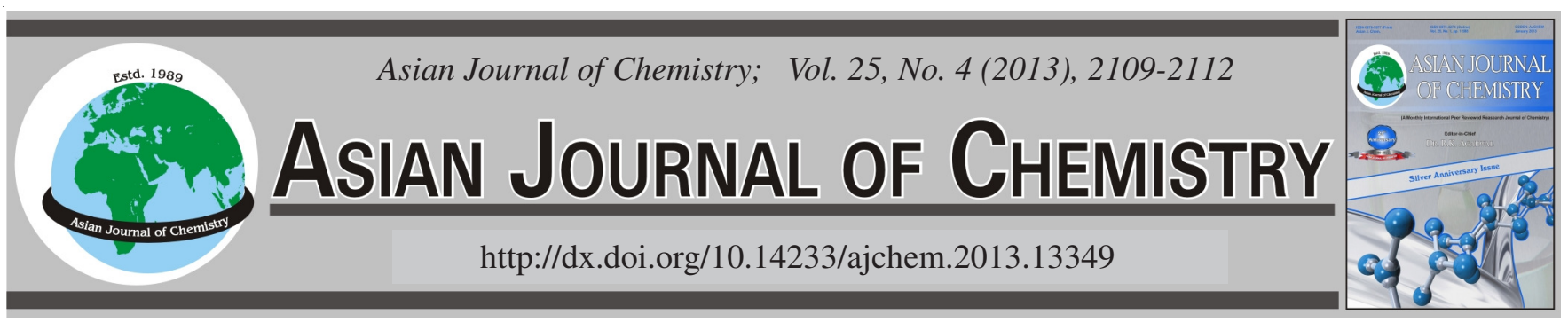

\title{
Excess Volumes of Binary Liquid Mixtures of Benzene and Carbon Tetrachloride with Cumene and Pseudocumene
}

\author{
K. YADAV ${ }^{1, *}$, ANITA KUMARI ${ }^{2}$ and M. KUMAR ${ }^{3}$
}

${ }^{1}$ Department of Chemistry, Samastipur College, Samastipur-848 134, Inida

${ }^{2}$ Department of Chemistry, Lalit Narayan Mishra University, Darbhanga-846 008, India

${ }^{3}$ Department of Chemsitry, S.M.R.C.K. College, Samastipur-848 101, Inida

*Corresponding author: E-mail: yadav.kusheshwar@yahoo.com; yadavkspj@gmail.com

\begin{abstract}
Densitites $(\rho)$, visocisities $(\eta)$ and ultrasonic velocities for binary liquid mixtures formed from benzene and carbon tetrachloride with cumene and psedocumene have been measured at two different temperatures 303.15 and $293.15 \mathrm{~K}$. Excess volume of mixing $\left(v^{\mathrm{E}}\right)$, deviation of excess volume $\left(\Delta v^{\mathrm{E}}\right)$ from ideal mole fraction law and parameter (d) as a measure of strengh of interaction between components of binary mixtures have been calculated from the data of densities and viscosities. Excess volumes have been found to be negative and positive in sign for binary mixtrue of carbon tetrachloride with cumene and pseudocumene and carbon tetrachloride with benzene at entire mole-fraction range and at both temperatures 303.15 and $293.15 \mathrm{~K}$. On the other hand, $\Delta \eta$ were found to be negative for binary mixtures of carbon tetrachloride with cumene and pseudocumene except the binary mixture of carbon tetrachloride with benzene at entire mole fraction range and temperatures mentioned. Positive value of excess volumes for three mixtures (carbon tetrachloride with benzene, cumene and pseudocumene) show weak molecular interactions between components. However, the negative value of $\Delta \eta$ for binary mixtures of carbon tetrachloride with cumene and pseudocunene show weak interactions between components. The experimental values of excess volumes of mixing $\left(v^{\mathrm{E}}\right)$ have been analyzed in the light of Flory's theory.
\end{abstract}

Key Words: Excess volumes, Deviation, Carbon tetrachloride, Molecular interaction, Flory's theory, Cumene and pseudocumene.

ᄂ _ - - - - - - - - - - - - - - - - - - - - - - - - - - - -

\section{INTRODUCTION}

In recent years the molecular interaction in varoius binary liquid mixtures by several authors ${ }^{1-6}$ through, volumetric, viscometric and ultrasonic studies have got considerable importance in framing theoretical models as well as its applications in a number of branches of science. The present work deals with the study of excess volumes of binary liquid mixtures of benzene and carbon tetrachloride with cumene and pseudocumene at entire molecular range and at temperatures 303.15 and $293.15 \mathrm{~K}$. The regular trend in variation of $v^{\mathrm{E}}$ and $\Delta \eta$ for binary mixtures ${ }^{7}$ has not been found in present case. Some of the mixtures show positive ${ }^{8}$ sign while other show negative sign for both $v^{\mathrm{E}}$ and $\Delta \eta$ wich shows the existence of some specific interactions ${ }^{9,10}$ there in. Negative values of both $\nu^{\mathrm{E}}$ and $\Delta \eta$ for carbon tetrachloride + cumene + pseudocumene counter balance their effects showing some weak specific interaction between unlike components. Excess volumes of mixing $\left(v^{\mathrm{E}}\right)$, may be calculated from density ${ }^{11}$ measurements, have been compared with theoretical values calculated on the basis of Flory's theory ${ }^{12,13}$.

\section{EXPERIMENTAL}

Carbon tetrachloride (A.R., B.D.H) was purified by vigorous shaking with dil. $\mathrm{NaOH}$ solution and then fractionally distilled over $\mathrm{P}_{2} \mathrm{O}_{5}$ and stored.

Benzene (A.R., B.D.H) was shaken with conc. $\mathrm{H}_{2} \mathrm{SO}_{4}$ to remove trace of thiophene present if any. It was then washed with $10 \% \mathrm{Na}_{2} \mathrm{CO}_{3}$ solution followed by distilled water till free from alkali. It was then dried over anhydrous $\mathrm{CaCl}_{2}$, fractionally distilled over $\mathrm{P}_{2} \mathrm{O}_{5}$ and stored over Na-wire. Cumene (Fluka Chemika) and pseudocumene (Fluka Chemika) both were distilled thrice by fractional distillation process. The purities of different component liquids were verified by density measurement. Binary liquid mixtures of varying composition were prepared.

\section{RESULTS AND DISCUSSION}

Excess volumes $\left(v^{\mathrm{E}}\right)$ of binary liquid miexture of varying composition were calculated by using-relation

$$
v^{\mathrm{E}}=v^{\mathrm{obs}}-v^{\text {id }}
$$

where $v^{\text {obs }}$ is the experimental value of volume of binary liquid mixture. 


\begin{tabular}{|c|c|c|}
\hline \multicolumn{3}{|c|}{$\begin{array}{c}\text { EXPERIMENTAL VALUES OF EXCESS } \\
\text { VOLUMES }\left(v^{\mathrm{E}}\right) \text { OF BINARY MIXTURE } \\
(\text { CUMENE + BENZENE) AT 303.15 AND } 293.15 \mathrm{~K}\end{array}$} \\
\hline $\begin{array}{l}\text { Mole fraction of } \\
\text { cumene }\end{array}$ & $\begin{array}{l}\text { Volume excess } \\
v^{\mathrm{E}}\left(\text { c.c. } \mathrm{mol}^{-1}\right)\end{array}$ & $\begin{array}{l}\text { Deviation from quation } \\
\left(\Delta v^{E}\right) \text { (from Table-5) }\end{array}$ \\
\hline \multicolumn{3}{|c|}{ Temp. 303.15 K } \\
\hline 0.0900 & 0.043 & +0.001 \\
\hline 0.2008 & 0.082 & +0.000 \\
\hline 0.3048 & 0.106 & +0.001 \\
\hline 0.5100 & 0.113 & -0.001 \\
\hline 0.5500 & 0.109 & -0.001 \\
\hline 0.6008 & 0.105 & +0.001 \\
\hline 0.7081 & 0.085 & +0.002 \\
\hline 0.8005 & 0.061 & +0.002 \\
\hline 0.9151 & 0.025 & -0.001 \\
\hline \multicolumn{3}{|c|}{ Temp. $293.15 \mathrm{~K}$} \\
\hline 0.1008 & 0.052 & +0.000 \\
\hline 0.2405 & 0.101 & +0.001 \\
\hline 0.3100 & 0.115 & +0.001 \\
\hline 0.4300 & 0.126 & +0.002 \\
\hline 0.5150 & 0.120 & -0.001 \\
\hline 0.6008 & 0.110 & -0.001 \\
\hline 0.7215 & 0.085 & -0.001 \\
\hline 0.8005 & 0.065 & +0.001 \\
\hline
\end{tabular}

\begin{tabular}{ccc}
\multicolumn{3}{c}{ TABLE-2 } \\
$\begin{array}{c}\text { EXPERIMENTAL VALUES OF EXCESS VOLUMES } \\
\left(v^{\mathrm{E}}\right) \text { OF BINARY MIXTURES (PSEUDOCUEMENE } \\
+ \text { BENZENE) AT 303.15 AND 293.15 K }\end{array}$ \\
\hline $\begin{array}{c}\text { Mole fraction of } \\
\text { pseudocumene }\end{array}$ & $\begin{array}{c}\text { Volume excess } \\
v^{\mathrm{E}}\left(\text { c.c. } \text { mol }^{-1}\right)\end{array}$ & $\begin{array}{c}\text { Deviation from quation } \\
\left(\Delta v^{\mathrm{E}}\right)\end{array}$ \\
\hline \multicolumn{3}{c}{ (from Table-5) } \\
\hline 0.0958 & 0.125 & +0.002 \\
0.2008 & 0.235 & -0.001 \\
0.3516 & 0.337 & +0.001 \\
0.4590 & 0.355 & +0.001 \\
0.4900 & 0.322 & +0.001 \\
0.4900 & 0.322 & -.001 \\
0.7150 & 0.243 & +0.001 \\
0.8056 & 0.167 & +0.001 \\
0.9085 & 0.075 & +0.002 \\
\hline \multicolumn{3}{c}{ Temp. } \\
\hline 0.2008 & Temp. $293.15 \mathrm{~K}$ & +0.002 \\
0.3156 & 0.251 & +0.001 \\
0.4900 & 0.335 & -0.003 \\
0.6008 & 0.369 & +0.002 \\
0.7500 & 0.340 & -0.001 \\
0.8600 & 0.235 & +0.002 \\
\hline
\end{tabular}

$$
v^{\text {obs }}=\frac{M_{1} x_{1}+M_{2} x_{2}}{\rho}
$$

where $\rho$ is the density of binary liquid mixture of given composition measured. $v^{\text {id }}$ refers to the value for ideal binary mixture.

$$
v^{\text {id }}=x_{1} v_{1}^{0}+x_{2} v_{2}^{0}=\frac{x_{1} M_{1}}{\rho_{1}}+\frac{x_{2} M_{2}}{\rho_{2}}
$$

where $M_{1}$ and $M_{2}$ are the molar masses ${ }^{14,15}, \rho_{1}$ and $\rho_{2}$ are densities of component liquids in pure state as well as $\mathrm{x}_{1}$ and $\mathrm{x}_{2}$ are the mole fractions of first and second components in

\begin{tabular}{|c|c|c|}
\hline \multicolumn{3}{|c|}{$\begin{array}{c}\text { TABLE-3 } \\
\text { EXPERIMENTAL VALUES OF EXCESS VOLUMES } \\
\left(v^{\mathrm{E}}\right) \text { OF BINARY MIXTURES (CUMENE + CARBON } \\
\text { TETRACHLORIDE) AT 303.15 AND 293.15 K }\end{array}$} \\
\hline $\begin{array}{l}\text { Mole fraction of } \\
\text { cumene }\end{array}$ & $\begin{array}{l}\text { Volume excess } \\
\left.\mathrm{v}^{\mathrm{E}} \text { (c.c. } \mathrm{mol}^{-1}\right)\end{array}$ & $\begin{array}{c}\text { Deviation from quation } \\
\left(\Delta v^{E}\right) \text { (from Table-5) }\end{array}$ \\
\hline \multicolumn{3}{|c|}{ Temp. $303.15 \mathrm{~K}$} \\
\hline 0.1501 & 0.006 & +0.000 \\
\hline 0.2008 & 0.007 & +0.001 \\
\hline 0.3016 & 0.004 & +0.000 \\
\hline 0.3800 & 0.001 & +0.000 \\
\hline 0.4500 & -0.002 & -0.001 \\
\hline 0.5196 & -0.004 & +0.000 \\
\hline 0.5300 & -0.005 & -0.001 \\
\hline 0.6602 & -0.010 & -0.001 \\
\hline 0.7050 & -0.011 & -0.001 \\
\hline 0.8101 & -0.010 & +0.000 \\
\hline 0.8504 & -0.010 & +0.000 \\
\hline \multicolumn{3}{|c|}{ Temp. 293.15 K } \\
\hline 0.1005 & 0.003 & +0.000 \\
\hline 0.1700 & 0.004 & +0.001 \\
\hline 0.2812 & 0.002 & +0.001 \\
\hline 0.3500 & 0.000 & +0.000 \\
\hline 0.4500 & -0.003 & +0.000 \\
\hline 0.5550 & -0.007 & +0.001 \\
\hline 0.6900 & -0.014 & +0.000 \\
\hline 0.8405 & -0.013 & +0.001 \\
\hline 0.8905 & -0.012 & +0.000 \\
\hline
\end{tabular}
mixture.

\begin{tabular}{|c|c|c|}
\hline \multicolumn{3}{|c|}{$\begin{array}{c}\text { TABLE-4 } \\
\text { EXPERIMENTAL VALUES OF EXCESS VOLUMES } \\
\left(v^{\mathrm{E}}\right) \text { OF BINARY MIXTURES (PSEUDOCUMENE + CARBON } \\
\text { TETRACHLORIDE) AT 303.15 AND 293.15 K }\end{array}$} \\
\hline $\begin{array}{c}\text { Mole fraction of } \\
\text { pseudocumene }\end{array}$ & $\begin{array}{l}\text { Volume excess } \\
v^{\mathrm{E}}\left(\text { c.c. } \mathrm{mol}^{-1}\right)\end{array}$ & $\begin{array}{l}\text { Deviation from quation } \\
\left(\Delta v^{E}\right) \text { (from Table-5) }\end{array}$ \\
\hline \multicolumn{3}{|c|}{ Temp. $303.15 \mathrm{~K}$} \\
\hline 0.1005 & 0.036 & -0.001 \\
\hline 0.2108 & 0.078 & +0.001 \\
\hline 0.4500 & 0.134 & -0.001 \\
\hline 0.5056 & 0.144 & +0.001 \\
\hline 0.6001 & 0.146 & +0.002 \\
\hline 0.7514 & 0.114 & -0.001 \\
\hline 0.8700 & 0.070 & -0.001 \\
\hline 0.9100 & 0.050 & +0.000 \\
\hline \multicolumn{3}{|c|}{ Temp. 293.15 K (from Table-6) } \\
\hline 0.1508 & 0.066 & +0.001 \\
\hline 0.2008 & 0.085 & +0.001 \\
\hline 0.3508 & 0.126 & -0001 \\
\hline 0.4500 & 0.144 & +0.001 \\
\hline 0.5052 & 0.147 & -0.001 \\
\hline 0.6100 & 0.148 & +0.002 \\
\hline 0.7512 & 0.120 & +0.000 \\
\hline 0.8609 & 0.077 & -0.002 \\
\hline
\end{tabular}

Thus,

$$
v^{E}=\frac{M_{1} x_{1}+M_{2} x_{2}}{\rho}+\left[\frac{x_{1} M_{1}}{\rho_{1}}+\frac{x_{2} M_{2}}{\rho_{2}}\right]
$$

where $v^{\mathrm{E}}$ is the excess volume of mixing which can be obtained from following empirical equation derived by the method of least square using only three parameters ${ }^{16}$.

$$
v^{\mathrm{E}}=\mathrm{x}_{1} \mathrm{x}_{2}\left[\mathrm{~A}+\mathrm{B}\left(\mathrm{x}_{2}-\mathrm{x}_{2}\right)+\mathrm{C}\left(\mathrm{x}_{1}-\mathrm{x}_{2}\right)^{2}\right]
$$

where $\mathrm{A}, \mathrm{B}$ and $\mathrm{C}$ are characteristic constants of first and second components. Tables 1-4 constants for binary mixtures as well as $\mathrm{x}_{1}$ and $\mathrm{x}_{2}$ are mole. 
The quations given in Tables 5-7 have been obtained from the experimental values of excess volume of mixing $\left(v^{\mathrm{E}}\right)$ for binary liquid mixtures of cumene + benzene, pseudocumene + benzene, cumene + carbon tetrachloride and pseudocumene + carbon tetrachloride at different temperatures by the use of the method least square. These are given by the following equation $^{18,19}$.

$$
v^{\mathrm{E}} \operatorname{mol}^{-1} \mathrm{c} . \mathrm{c}=\mathrm{x}_{1} \mathrm{x}_{2}\left[\mathrm{~A}+\mathrm{B}\left(\mathrm{x}_{1}-\mathrm{x}_{2}\right)+\mathrm{C}\left(\mathrm{x}_{1}-\mathrm{x}_{2}\right)\right]
$$

where $\mathrm{x}_{1}$ represents the mole fraction of first component (cumene or pseudocumene) and $\mathrm{x}_{2}$ represents the mole fraction of second component (benzene or carbon tetrachloride). A, B and $\mathrm{C}$ are fitting constants of binary mixtures concerned, which have been obtained by the method of least squares. The values of these constant $\mathrm{s}^{20}$ vary from one binary mixture to other and from one temperature to other, can be seen in individual equation enlisted in Tables 5-7. The last column of these tables present the standard deviation $\left(\sigma \Delta v^{\mathrm{E}}\right)$ which has been calculated using the following equation.

$$
\sigma \Delta v^{\mathrm{E}} \mathrm{mol}^{-1} \mathrm{c} . \mathrm{c}=\left[\frac{\Sigma\left(\Delta v^{\mathrm{E}}\right)^{2}}{(\mathrm{~m}-\mathrm{n})}\right]^{1 / 2}
$$

where $\Delta v^{\mathrm{E}}$ is deviation in the experimental values of excess volume from that calculated from eqn. 6 and ' $\mathrm{m}$ ' is the number of observations as well as ' $n$ ' is the member of constants used in eqn. 6.

Equations recorded in Table-7 represent the general form for $\mathrm{v}^{\mathrm{E}}$ of binary liquid mixture ${ }^{21}$ (temp. T K). These equations recorded in the Tables 5-7 for binary systems under investigation fit satisfactorily the experimentally observed values of $v^{\mathrm{E}}$. The last column of Table-7 gives the values of $\delta v^{\mathrm{E}} / \delta \mathrm{T}$ for equimolar binary mixture ${ }^{22}$.

After analysis of the results so obtained it is found that positive values of excess volume of mixing have been found for binary liquid mixtures of cumene and pseudocumene with benzene at entire mole fraction range $\mathrm{e}^{23}$ and at all the temperatures i.e., 293.15 and $303.15 \mathrm{~K}$. On the other hand both positive and negative values of volume excess have been found for binary liquid mixtures of cumene and carbon tetrachloride at the temperatures 293.15 and $303.15 \mathrm{~K}$. It can be seen that positive values are found at lower mole fraction range and negative values at higher mole fraction range of cumene. However, positive values of volume excess could be observed for binary mixture of carbon tetrachloride with pseudocumene at entire mole fraction range and at both the temperatures i.e., 293.15 and $303.15 \mathrm{~K}$.

The comparative plot $^{24}$ of excess volumes $\left(v^{\mathrm{E}}\right)$ for binary liquid mixtures ${ }^{25-27}$ of pseudocumene and cumene with benzene and carbon tetrachloride, plotted in the Fig. 1, shows that the values of excess volume of mixing $\left(v^{\mathrm{E}}\right)$ are maximum at almost all mole fraction range for the binary liquid mixture of pseudocumene with benzene. The volume excess of equimolal mixtures of cumene and pseudocumene with benzene and carbon tetrachloride are $0.1155,0.3528$ and -0.0034 c.c. mol $^{-1}$ at $303.15 \mathrm{~K}$.

\section{Conclusion}

The experimental data of excess volumes of mixing $\left(v^{\mathrm{E}}\right)$ are reported for binary mixtures of cumene and pseudocumene with benzene and carbon tetrachloride over entire range of mole fractions at 303.15 and 293.15 K. Calculated excess volume of mixing $\left(v^{\mathrm{E}}\right)$ and its deviation $\left(\Delta v^{\mathrm{E}}\right)$ are fitted in Redlich Kister type polynomial equations. A slight positive and negative deviations are observed for both the investigated binary systems. The present investigation shows that excess volumes of mixing are in the order of: pseudocumene + benzene $>$ pseudocumene + carbon tetrachloride $>$ cumene + benzene $>$ cumene + carbon tetrachloride.

TABLE-5

EQUATIONS FITTING THE DATA FOR EXCESS VOLUME OF MIXING ( $v^{\mathrm{E}} /$ c.c. mol-1) TEMP. $303.15 \mathrm{~K}$

\begin{tabular}{llc}
\hline \multicolumn{1}{c}{ System } & \multicolumn{1}{c}{ Equation fitting the experimental data } & Std. deviation $\left(6 \Delta v^{\mathrm{E}}\right)$ \\
\hline Cumene + benzene $\left(\mathrm{x}_{1}\right)$ & $v^{\mathrm{E}}=\mathrm{x}_{1} \mathrm{x}_{1}\left[0.4621-0.1171\left(\mathrm{x}_{1}-\mathrm{x}_{2}\right)-0.0546\left(\mathrm{x}_{1}-\mathrm{x}_{2}\right)^{2}\right]$ & 0.0015 \\
Pseudocumene + benzene $\left(\mathrm{x}_{1}\right)$ & $v^{\mathrm{E}}=\mathrm{x}_{1} \mathrm{x}_{2}\left[1.4112-0.3352\left(\mathrm{x}_{1}-\mathrm{x}_{2}\right)-0.3873\left(\mathrm{x}_{1}-\mathrm{x}_{2}\right)^{2}\right]$ & 0.0016 \\
Cumene + carbon tetrachloride $\left(\mathrm{x}_{1}\right)$ & $v^{\mathrm{E}}=\mathrm{x}_{1} \mathrm{x}_{2}\left[-0.0137-0.0944\left(\mathrm{x}_{1}-\mathrm{x}_{2}\right)-0.0104\left(\mathrm{x}_{1}-\mathrm{x}_{2}\right)^{2}\right]$ & 0.0007 \\
Pseudocumene + carbon tetrachloride $\left(\mathrm{x}_{2}\right)$ & $v^{\mathrm{E}}=\mathrm{x}_{1} \mathrm{x}_{2}\left[0.5634+0.1360\left(\mathrm{x}_{1}-\mathrm{x}_{2}\right)-0.0592\left(\mathrm{x}_{1}-\mathrm{x}_{2}\right)^{2}\right]$ & 0.0014 \\
\hline
\end{tabular}

TABLE-6

EQUATIONS FITTING THE DATA FOR EXCESS VOLUME OF MIXING ( $v^{\mathrm{E}} /$ c.c. mol-1) TEMP. $293.15 \mathrm{~K}$

\begin{tabular}{llc}
\multicolumn{4}{c}{ EQUATIONS FITTING THE DATA FOR EXCESS VOLUME OF MIXING $\left(v^{\mathrm{E}} /\right.$ c.c. mol-1) TEMP. $293.15 \mathrm{~K}$} \\
\hline \multicolumn{1}{c}{ System } & \multicolumn{1}{c}{ Equation fitting the experimental data } & Std. deviation $\left(6 \Delta v^{\mathrm{E}}\right)$ \\
\hline Cumene + benzene $\left(\mathrm{x}_{1}\right)$ & $v^{\mathrm{E}}=\mathrm{x}_{1} \mathrm{x}_{1}\left[0.4911-0.1294\left(\mathrm{x}_{1}-\mathrm{x}_{2}\right)-0.0293\left(\mathrm{x}_{1}-\mathrm{x}_{2}\right)^{2}\right]$ & 0.0014 \\
Pseudocumene + benzene $\left(\mathrm{x}_{1}\right)$ & $v^{\mathrm{E}}=\mathrm{x}_{1} \mathrm{x}_{2}\left[1.4836-0.2987\left(\mathrm{x}_{1}-\mathrm{x}_{2}\right)-0.3005\left(\mathrm{x}_{1}-\mathrm{x}_{2}\right)^{2}\right]$ & 0.0027 \\
Cumene + carbon tetrachloride $\left(\mathrm{x}_{1}\right)$ & $v^{\mathrm{E}}=\mathrm{x}_{1} \mathrm{x}_{2}\left[-0.0226-0.0986\left(\mathrm{x}_{1}-\mathrm{x}_{2}\right)-0.0387\left(\mathrm{x}_{1}-\mathrm{x}_{2}\right)^{2}\right]$ & 0.0008 \\
Pseudocumene + carbon tetrachloride $\left(\mathrm{x}_{2}\right)$ & $v^{\mathrm{E}}=\mathrm{x}_{1} \mathrm{x}_{2}\left[0.5913-0.1074\left(\mathrm{x}_{1}-\mathrm{x}_{2}\right)-0.0065\left(\mathrm{x}_{1}-\mathrm{x}_{2}\right)^{2}\right]$ & 0.0016 \\
\hline
\end{tabular}

TABLE-7

EQUATIONS FITTING THE DATA FOR EXCESS VOLUME OF MIXING $\left(v^{\mathrm{E}} /\right.$ c.c. mol-1) TEMP. T K

\begin{tabular}{lll}
\hline \multicolumn{1}{c}{ System } & \multicolumn{1}{c}{ Equation fitting the experimental data } & $\mathrm{D} v^{\mathrm{E}} / \mathrm{Dt}$ \\
\hline Cumene + benzene $\left(\mathrm{x}_{1}\right)$ & $v^{\mathrm{E}}=\mathrm{x}_{1} \mathrm{x}_{1}\left[1.3414-0.0030 \mathrm{t}+(-0.4901+0.00124 \mathrm{~T})\left(\mathrm{x}_{1}-\mathrm{x}_{2}\right)+\left(0.7123-0.00253\left(\mathrm{x}_{1}-\mathrm{x}_{2}\right)^{2}\right]\right.$ & -0.00075 \\
Pseudocumene + benzene $\left(\mathrm{x}_{1}\right)$ & $v^{\mathrm{E}}=\mathrm{x}_{1} \mathrm{x}_{1}\left[(3.6064-0.00725 \mathrm{~T})+(-0.7710-0.00366 \mathrm{~T})\left(\mathrm{x}_{1}-\mathrm{x}_{2}\right)+\left(2.2439-0.00865 \mathrm{~T}\left(\mathrm{x}_{1}-\mathrm{x}_{2}\right)^{2}\right]\right.$ & -0.00181 \\
Cumene + carbon tetrachloride $\left(\mathrm{x}_{1}\right)$ & $v^{\mathrm{E}}=\mathrm{x}_{1} \mathrm{x}_{1}\left[(-0.2829+0.000889 \mathrm{~T})+(0.22190 .00043 \mathrm{~T})\left(\mathrm{x}_{1}-\mathrm{x}_{2}\right)+\left(-0.8680+0.00285 \mathrm{~T}\left(\mathrm{x}_{1}-\mathrm{x}_{2}\right)^{2}\right]\right.$ & 0.00022 \\
Pseudocumene + carbon tetrachloride $\left(\mathrm{x}_{2}\right)$ & $v^{\mathrm{E}}=\mathrm{x}_{1} \mathrm{x}_{1}\left[(1.4090-0.00278 \mathrm{~T})+(0.7309+0.00284 \mathrm{~T})\left(\mathrm{x}_{1}-\mathrm{x}_{2}\right)+\left(1.5385-0.00530 \mathrm{~T}\left(\mathrm{x}_{1}-\mathrm{x}_{2}\right)^{2}\right]\right.$ & -0.00069 \\
\hline
\end{tabular}




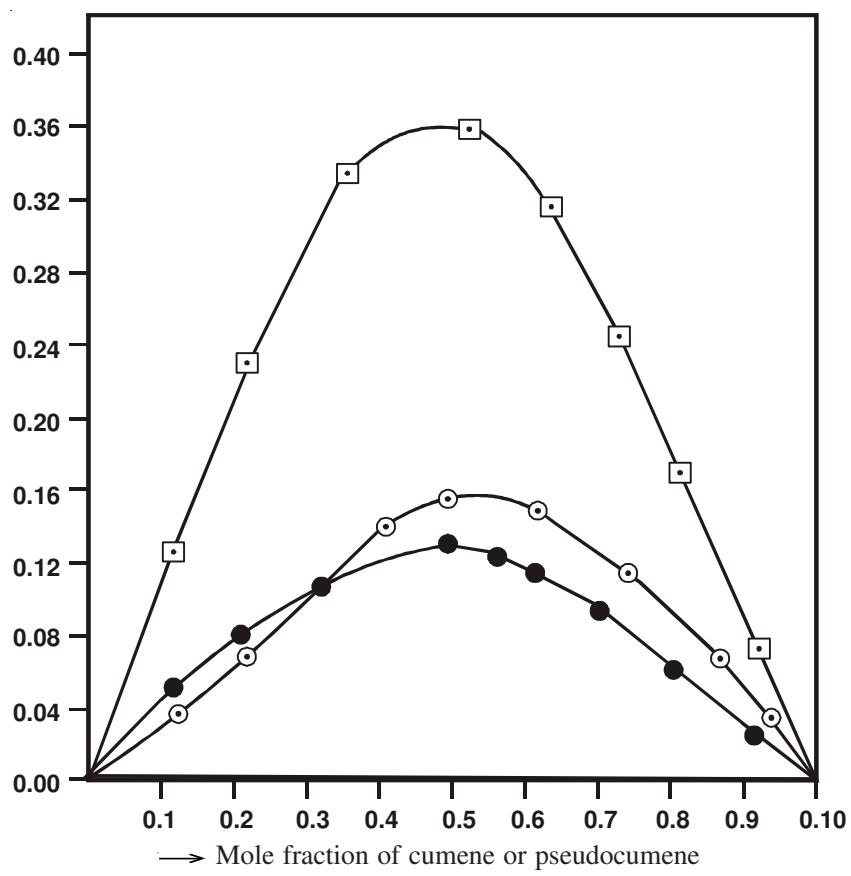

Fig. 1. Excess volume of mixing for $(\mathbf{O})$ : Pseudocumene + carbon tetrachloride. $(\odot)$ : Cumene + benzene. $(\bullet)$ : Pseudocumene + benzene

\section{ACKNOWLEDGEMENTS}

The authors are grateful to Dr. A.K. Gupta, University Deptt. of Chemistry, LNMU-Darbhanga for his valuable suggestions and are thankful to the staffs of Chemistry Department, Samastipur College, Samastipur for their helpful attitude.

\section{REFERENCES}

1. A.K. Gupta, C.K. Yadav and A.S. Ansari, Asian J. Chem., 9, 493 (1997).

2. R.P. Verma and A. Singh, Indian J. Pure Appl. Phys., 26, 606 (1988).

3. K.S. Mehra, Indian J. Pure Appl. Phys., 38, 760 (2000).

4. K.R. Prasad and P.S. Naidu, Indian J. Pure Appl. Phys., 41, 686 (2003).

5. A.K. Gupta, C.K. Yadav and K. Kumar, J. Indian Coun. Chem., 21, 28 (2004).

6. A.K. Nain, Bull. Chem. Soc. (Japan), 79, 1688 (2006).

7. A.K. Gupta and C.K. Yadav, Asian J. Chem., 9, 112 (1997).

8. Y.M. Al-Wahaibi, C.A. Grattoni and A.H. Muggeridge, J. Chem. Eng. Data, 52, 548 (2007).

9. M. Ciler and D. Kesanovil, Hydrogen Bonding, Peragamon Press, London, 7 (1957).

10. P.G. Dubey and M. Sharma, Phys. Chem. Liq., 46, 610 (2008).

11. A.K. Gupta, K. Kumar and B.K. Karn, J. Indian Coun. Chem., 26, 77 (2009).

12. P.J. Flory, J. Am. Chem. Soc., 87, 1833 (1965).

13. A. Abe and P.J. Flory, J. Am. Chem. Soc., 87, 1838 (1965).

14. A.M. Ali, R. Parashar, A. Saxena and M.L. Lakhanpal, Indian J. Chem., 28, 512 (2004)

15. B. Gonzalez, A. Domiguez and J. Tojo, J. Chem. Eng. Data, 51 (2006).

16 L. Grunberg and A.H. Nissan, Nature, 164, 799 (1949).

17. J. Timmermann, Physico-Chemical Constants of Pure Organic Compounds, Elsevier, Amsterdom (1950).

18. R.J. Fort and W.R. Moore, Trans. Faraday Soc., 61, 2102 (1965).

19. R.J. Large Man and W.S. Dundbar, J. Phys. Chem., 49, 428 (1945).

20. R. Mehra, Indian J. Chem., 44A, 1834 (2005).

21. A. Ali and A.K. Nain, Indian J. Phys., 74B, 63 (2000).

22. G. Jones and M. Dole, J. Am. Chem. Soc., 51, 2950 (1929).

23. M. Dzida, J. Chem. Eng. Data, 52, 521 (2007).

24. P. Vasantharani,V. Pandiyan and A.N. Kanaoppan, Asian J. Appl.-Sci., 2, 169 (2009).

25. J. Li, M. Mundhwa, P. Tontiwachwuthikul and A. Henni, J. Chem. Eng. Data, 52, 560 (2007).

26. D. Sharma and S.N. Srivastava, Asian J. Chem., 18, 2756 (2006).

27. R. Palani, S. Saravanan and A. Geetha, Asian J. Chem., 19, 5113 (2007). 